\title{
Virus resistance transferred from human rheumatoid cells to rabbit synovial cells
}

\section{Methods and results of intra-articular injection of human cells into rabbit joints}

\author{
CAROL SMITH, * DAVID HAMERMAN, ROSAMOND JANIS, AND \\ EDWARD HABERMANN \\ From the Departments of Medicine and Orthopaedic Surgery, Montefiore Hospital and the \\ Albert Einstein College of Medicine, and the Department of Pathology, \\ Albert Einstein College of Medicine, Bronx, New York
}

In histological sections of the synovial membrane obtained from patients with rheumatoid arthritis, the lining cells display a number of alterations that distinguish them from the lining cells of the normal synovial membrane. The rheumatoid lining cells synthesize decreased amounts of a component immunologically related to cartilage protein polysaccharide, and demonstrate altered and enhanced lysosomal hydrolase activities (Hamerman, Barland, and Janis, 1969), which may account for the finding of an excess of reduced form of nicotinamide adenine dinucleotide phosphate in these cells (Chayen and Bitensky, 1971). Synovial cells originating from rheumatoid membranes after explant culture continue to manifest these differences in vitro (Smith and Hamerman, 1969). They also display increased glucose consumption and lactate production, and enhanced synthesis of hyaluronate (Castor, 1971). Rheumatoid synovial cells (RSC) in culture are also resistant to productive infection by Newcastle disease virus (NDV) (Smith and Hamerman, 1969) and rubella virus (RV) (Grayzel and Beck, 1970). In our hands, this resistance to exogenous virus infection is a unique property of the cultured RSC, providing an apparently specific 'rheumatoid trait'. Synovial cells derived from nonrheumatoid joints (NSC) including normal, psoriatic, and tuberculous arthritis, have proven susceptible to lytic infection with RV in 67 of seventy experiments. Over fifty RSC cultures have been tested and all but three have been resistant to cytolytic RV infection. The basis for this resistance is not known, but does not appear to be due to enhanced production of interferon by rheumatoid cells; indeed these cells seem less responsive than normal cells to interferon inducers (Grayzel and Beck, 1970).

An infectious agent has long been sought as the aetiologic basis for rheumatoid arthritis, but until recently there was little evidence for such a possibility. Reports have now appeared describing the isolation of diphtheroid organisms from rheumatoid joints (Stewart, Alexander, and Duthie, 1969; Bartholomew and Nelson, 1972), as well as a number of types of fastidious mycoplasma (Jansson, Mäkisara, Vainio, Vainio, Snellman, and Tuuri, 1971; Williams, Brostoff, and Roitt, 1970; Fraser, Shirodaria, Haire, and Middleton, 1971). However, recent studies fail to confirm the association of mycoplasma with rheumatoid joint tissues (Ward, Cole, and Smith, 1972). Despite numerous attempts using conventional techniques, no virus agent has been isolated from rheumatoid synovial membrane or synovial fluid (Smith and Hamerman, 1969). The possibility exists, however, that a latent virus persists in the RSC causing their resistance to exogenous virus infection and their altered metabolic reactions. This agent may be aetiologically related to rheumatoid arthritis.

In recent years new virus-host cell interactions have been demonstrated, whereby non-lytic virus infections result in persistence of the virus genome in cells producing either cell transformation (oncogenic viruses) or slowly evolving cell dysfunction (slow 
viruses) (Koprowski, 1967). Immunological methods, or techniques for virus rescue, have often been successful in revealing these latent virus genomes. This sort of interaction could explain the altered metabolism of RSC in culture, their resistance to RV or NDV infection, and could account for the failure to recover an aetiologic virus by conventional techniques. Further, the intensive immunoglobulin synthesis observed in the synovial membrane (Smiley, Sachs, and Ziff, 1968) may be initiated in response to an exogenous neo-antigen induced by an infectious agent.

We undertook two approaches in attempts to detect an agent in cultured RSC. In the first we sought to transfer in vivo the property of RV resistance from human RSC to rabbit synovial cells by injection of human RSC into normal rabbit joints. In the accompanying paper (p. 180) we describe results using a more direct attempt to 'rescue' a latent virus agent, $v i z$. cell fusion.

\section{Material and methods}

\section{CULTURE MEDIUM}

Dulbecco-modified Eagle's medium with 10 per cent. calf serum was used at all times unless otherwise noted.

SOURCES AND PREPARATION OF CULTURED CELLS The human RSC used for rabbit joint injection were obtained during open surgical procedures on diarthrodial joints from patients with classical or definite rheumatoid arthritis as defined by the American Rheumatism Association (Ropes, Bennett, Cobb, Jacox, and Jessar, 1959). NSC were obtained from patients of similar age with (a) tuberculous arthritis; (b) osteoarthritis; (c) traumatic injury to joints. Techniques for obtaining synovial cells in culture from synovial membrane specimens are described elsewhere (Hamerman, Janis, and Smith, 1967). Within 3 to 5 weeks of explanting, the synovial cells formed a confluent layer and were removed by trypsinization for subcultures to replicate dishes. Further serial subcultures were carried out at 10- to 14-day intervals.

\section{RABBIT JOINT INJECTION}

Before actual injection of cells into rabbit joints, the accuracy of the technique of joint injection was studied. Rabbits were restrained but not anaesthetized. The knee joint was shaved and $0.5 \mathrm{ml}$. of Hypaque was injected intra-articularly. Subsequent $x$ rays of the joint demonstrated localization of opaque material within the joint cavity.

Synovial cells were trypsinized and then washed once with serum-free culture medium. They were counted in a haemocytometer, and 300,000 cells suspended in $0.3 \mathrm{ml}$. of sterile phosphate buffered saline were injected via a 21-gauge needle into the knee joints of 3-month-old New Zealand female rabbits. A total of 28 rabbit joints were injected, thirteen with NSC and fifteen with RSC. The animals were killed after 2 to 6 months and specimens of knee joint synovial membrane and articular cartilage were obtained for histological study from four uninjected joints and from 26 injected joints. These specimens were fixed in 10 per cent. formalin and sections were stained with haematoxylin and eosin, and with safranin-O and fast green. Sterile specimens of synovial membrane were also obtained from each of the 28 injected rabbit joints and synovial cell cultures were prepared from these explants by methods similar to those used for human synovia. These rabbit synovial cell cultures were used subsequently for RV challenge.

DETERMINATION OF SUSCEPTIBILITY OF SYNOVIAL CELLS TO VIRUS INFECTION

Subcultures derived from rabbit synovial membrane explants were tested for virus sensitivity or resistance. Two rubella strains were used: F8, a large plaque variant, obtained from Dr. Philip Marcus, University of Connecticut, was harvested from monkey kidney cells; and M33, obtained from Hope Hopps at the National Institutes of Health, was harvested from normal human or rabbit synovial cells. One strain of NDV was used, which was supplied by Dr. Marcus.

For RV testing, each culture dish containing $10^{6}$ cells was infected with rubella at $10^{6}$ TCID. The TCID of rubella virus was determined by the method of Reed and Muench (Hoskins, 1967). Virus was added to the cultures in serum-free medium and incubated for $1 \mathrm{hr}$; the medium was removed and the cells were fed with fresh medium. The infected cultures received fresh medium changes twice weekly and were observed daily for the development of cytopathic effects and cell death.

For determination of NDV susceptibility, the single celko haemadsorption assay method was used (Marcus and? Carver, 1965). Plates containing $2 \times 10^{5}$ cells were infected with NDV, incubated for 18 to $22 \mathrm{hrs}$, and washed twice with phosphate buffered saline. Human type $O$ red cells were added for $30 \mathrm{~min}$. at $4^{\circ} \mathrm{C}$, and then washed eight times. 200 synovial cells were then counted, and the percentage showing adsorbed red cells on their membranes was recorded.

TITRE OF RV

To determine the ability of rabbit synovial cells to produce infectious RV, one culture dish of these cells derived from an NSC-injected joint and one from an RSC-injected joint were examined in the following manner: each dish was infected with RV as described above, but after $48 \mathrm{hrs}$ the cells were washed twice with serum-free medium, scraped off the culture plates, lysed in $1 \mathrm{ml}$. of serum-free medium by five cycles of freeze-thawing, and assayed for RV (Hoskins, 1967).

CHROMOSOME COUNTS (HAMERTON, 1971)

Chromosome preparations were made by the usual method, using colcemid to cause metaphase arrest, followed by swelling in hypotonic solution, fixation, and staining by the Giemsa method. 100 adequate chromosome spreads were counted to determine the average number of chromosomes per cell.

\section{Results}

\section{Synovial fluid from rabbit joints}

It was possible to aspirate about $0.5 \mathrm{ml}$. of turbid synovial fluid from only two joints; these had been 
previously injected with RSC. Routine laboratory cultures for fungi, bacteria, and mycoplasma were negative.

\section{Morphology and behaviour of cultured cells}

Since the morphology of the cultured rabbit synovial cells was consistently different from that of the human cells, all cultures could be easily identified as either rabbit or human by low power microscopic examination. The rabbit cells appeared uniformly bipolar, with large pale nuclei, and grew over the plates in an orderly fashion. Their final growth densities per plate were two to four times that of the human cells; they appeared both smaller and more closely arranged than their human counterparts. The human cells appeared more heterogeneous than the rabbit cells; some were bipolar but many contained multiple cell processes, often long or stellate; they grew over the plates in a more sparse and disorderly fashion.

Rabbit synovial cells remained diploid $(2 n=44)$ (Hsu and Benirschke, 1967) through at least fifteen cell generations after primary subculture. No chromosome studies were done after spontaneous degenerative aging changes began to appear. The rabbit cells had a rapid growth pattern, with an average doubling time during accelerated growth phase of 20 to $30 \mathrm{hrs}$ as compared to 40 to $72 \mathrm{hrs}$ for human synovial cells.

The rabbit synovial cells obtained from RSCinjected joints were compared with those isolated from NSC-injected joints (Figure A and B). There were no consistent differences in their morphology, growth rates, or culture life spans, although some observations were of interest: in three cultures out of fifteen, explants from the RSC-injected joints either failed to grow out to confluence, or to survive more than six generations after subculture; in no case did this occur with explants or cells from NSC-injected joints. Two other cultures derived from RSCinjected joints were made up of cells with a markedly prolonged generation time and low confluent density, as compared with their controls. At no time did any of the thirteen control cultures show such changes in their growth patterns.

\section{Histological studies}

Synovial membranes and cartilages were obtained from rabbit joints injected with either RSC, NSC, or
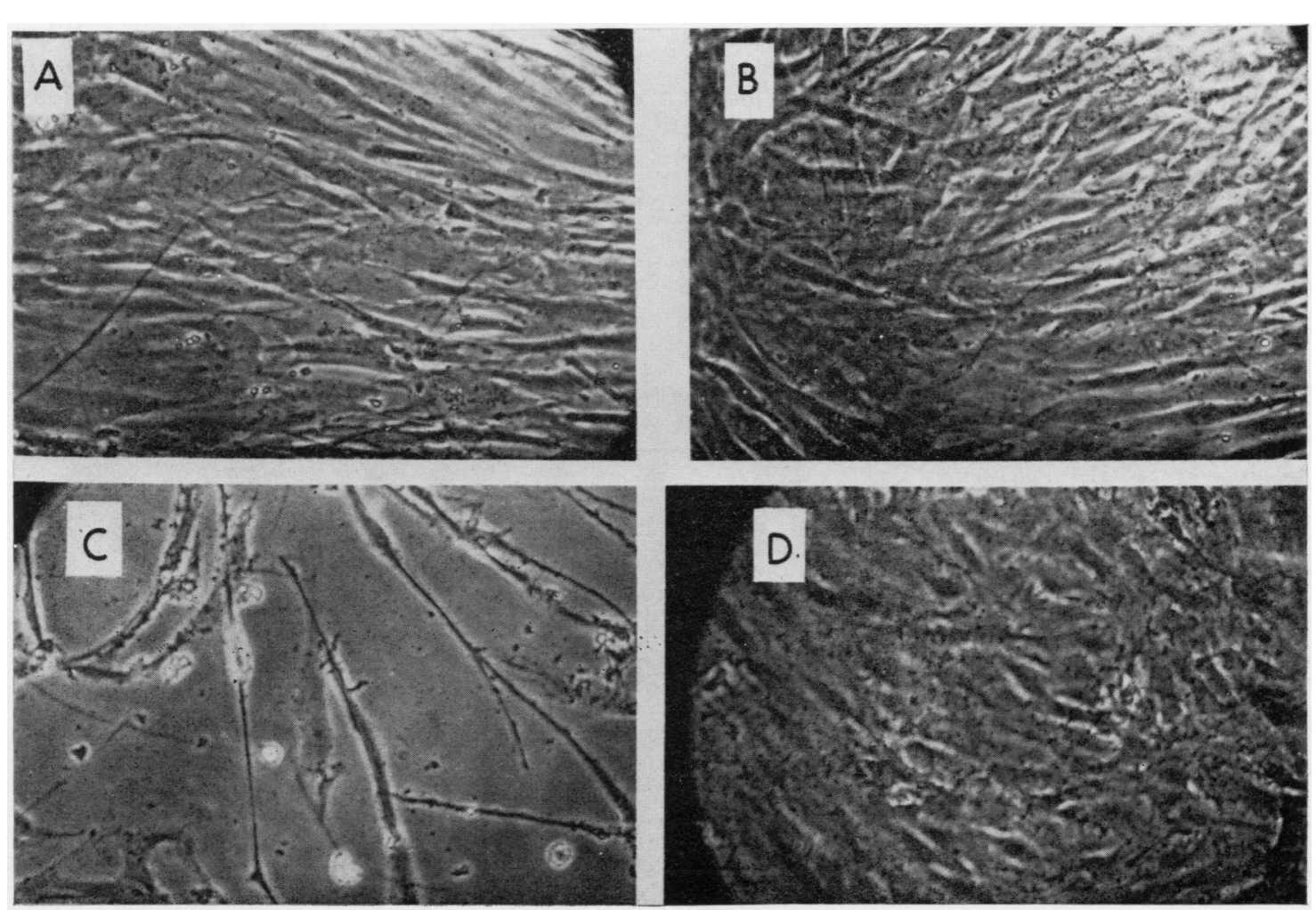

FIG URE Rabbit synovial membrane cells in culture. Cells derived from rabbit joints injected with human nonrheumatoid synovial cells are shown in $A$, while B depicts rabbit cells from joints injected with rheumatoid cells. The former developed cytopathic effects $(C) 14$ to 21 days after challenge with rubella virus, while the latter remained resistant to productive infection and could be serially sub-cultured $(D)$ 
no cells, and evaluated histologically. Several portions of synovial membrane were examined from each joint and graded for evidence of synovitis (Table I). Those with no significant abnormalities were called normal and graded 0 . Those which showed oedema, hyperaemia, sparse or mild inflammatory cell infiltration, and mild or focal synovial lining cell hyperplasia inclusive or with any combination of two of these were judged mildly inflamed and graded $1+$. Those with considerable inflammatory cell infiltration, lymphoid nodules, villous hypertrophy, prominent diffuse lining cell hyperplasia, and vascular proliferation inclusive or with any combination of at least two of these were judged markedly inflamed and graded $2+$.

Articular cartilages were examined by routine sectioning with both haematoxylin-eosin and safranin $\mathrm{O}$-fast green staining. The cartilage matrix protein-polysaccharide content was evaluated by the degree of intercellular basophilia and/or positive safranin $O$ staining (Table I). In the first group of twenty joints examined, random fragments of femoral condyle cartilage were selected for study; in the last group of ten joints examined, whole bone mounts of femoral condyles were sectioned and a more representative cap of articular cartilage surface evaluated. Those with strong and evenly distributed basophilia or safranin-positive staining were judged normal and graded 0 . Those graded as $1+$ showed either a mild diffuse diminution in basophilia or safranin-positive staining or small focal areas with such changes. Cartilages with diffuse and marked loss of matrix basophilia or safranin staining or with large focal areas exhibiting these changes were judged markedly depleted and graded $2+$. Several of these $2+$ cartilages also showed collapse of stroma with closely spaced and disarrayed chondrocytes. Histopathology of the rabbit joints previously injected with human RSC or NSC (Table I) revealed that 80 per cent. of those joints pre-injected with RSC showed significant synovitis $(1+$ and $2+)$ as compared to just slightly over 50 per cent. in joints pre-injected with NSC, or uninjected; 30 per cent. of this latter group (controls) showed marked $(2+)$ inflammatory changes, whereas only 13 per cent. of the RSC injected group showed severe synovitis. Cartilage matrix depletion (Table I) appeared to occur with comparable frequency in the two groups of joints. Of note, perhaps, is that the only three cartilages evaluated as normal ( 0 ) came from rabbit joints previously injected with NSC.

\section{Virus challenge of cultured cells}

Rabbit cell cultures were considered RV susceptible when all synovial cells died and detached from the plate within 14 to 21 days after challenge. A culture was considered RV resistant when it showed less than 25 per cent. cell death by the end of the same time period and the remaining cells survived additional subcultures (Figure $C$ and $D$ ).

Table II shows the results of these studies. When NSC were used for rabbit joint injection, subsequen rabbit synovial cell cultures were consistently susceptible to infection with RV and showed marked cytopathic effects and cell death. Unchallenged control cultures never showed such cytopathic effects. When human RSC were used for rabbit joint injection, the subsequent rabbit synovial cell cultures were resistant to $\mathrm{RV}$ challenge in all but three instances.

Table I Comparison and summary of histological changes in rabbit joints after injection of either nonrheumatoid (NSC) or rheumatoid (RSC) synovial cells

\begin{tabular}{|c|c|c|c|c|c|c|c|c|}
\hline \multirow[t]{2}{*}{ Rabbit joints } & \multicolumn{4}{|l|}{ Synovitis } & \multicolumn{4}{|c|}{ Cartilage matrix depletion } \\
\hline & None $(0)$ & Mild $(1+)$ & Marked (2+) & Total & None $(0)$ & $\operatorname{Mild}(1+)$ & Marked (2+) & Total \\
\hline $\begin{array}{l}\text { No. injected with NSC } \\
\text { or no cells at all }\end{array}$ & 8 & 2 & 5 & 15 & 3 & 5 & 5 & 13 \\
\hline No. injected with RSC & 3 & 10 & 2 & 15 & 0 & 7 & 7 & 14 \\
\hline
\end{tabular}

Table II Results of injection of nonrheumatoid (NSC) or rheumatoid (RSC) synovial cells into rabbit joints, and subsequent challenge of the cultured rabbit synovial cells with rubella virus $(R V)$ or Newcastle disease virus (NDV)

\begin{tabular}{|c|c|c|c|c|c|c|c|}
\hline \multirow{2}{*}{$\begin{array}{l}\text { No. of } \\
\text { rabbit joints }\end{array}$} & \multirow{2}{*}{$\begin{array}{l}\text { Cells } \\
\text { injected }\end{array}$} & \multicolumn{3}{|l|}{$R V$} & \multicolumn{3}{|l|}{$N D V$} \\
\hline & & $\begin{array}{l}\text { Total } \\
\text { tested }\end{array}$ & Resistant & Susceptible & $\begin{array}{l}\text { Total } \\
\text { tested }\end{array}$ & Resistant & Susceptible \\
\hline $\begin{array}{l}13 \\
15\end{array}$ & $\begin{array}{l}\text { NSC } \\
\text { RSC }\end{array}$ & $\begin{array}{l}13 \\
15\end{array}$ & $\begin{array}{r}0 \\
12\end{array}$ & $\begin{array}{r}13 \\
3\end{array}$ & $\begin{array}{l}4 \\
7\end{array}$ & $\begin{array}{l}0 \\
7\end{array}$ & $\begin{array}{l}4 \\
0\end{array}$ \\
\hline
\end{tabular}


The titre of RV was determined in rabbit synovial cells derived from one joint previously injected with NSC and from another previously injected with RSC. After $48 \mathrm{hrs,} \mathrm{rabbit} \mathrm{cells} \mathrm{from} \mathrm{the} \mathrm{NSC-}$ injected joint produced $\mathrm{RV}$ at a titre of $10^{6} \mathrm{TCID} / \mathrm{ml}$; rabbit cells from the $\mathrm{RSC}$-injected joint produced only $10^{2} \mathrm{TCID} / \mathrm{ml}$. These findings indicate productive infection with RV of rabbit cells derived from the NSC-injected joint; some infectious RV is present within rabbit cells from the RSC-injected joint, but either the titre is too low to produce cytopathic effects or else only some of those rabbit cells are infected.

Of the rabbit cell cultures challenged with NDV, the four rabbit cultures from joints previously injected with NSC showed a 60 to 90 per cent. haemadsorption positive count, while the seven rabbit cultures derived from RSC-injected joints showed 10 to 63 per cent. positive counts (Table II). Thus, some overlap was seen, but on individual test days, the cultures from NSC-injected joints always showed at least 20 per cent. more haemadsorption positive cells than those cultures derived from rabbit joints injected with RSC.

\section{Discussion}

The major observations resulting from injection of human NSC and RSC into rabbit joints are as follows:

(1) Rabbit synovial cells in culture derived from injected rabbit joints could be easily distinguished from human synovial cells. First, the human synovial cells would not be expected to survive in vivo in the rabbit joint for periods ranging from 2 to 6 months; second, the morphology of the rabbit cells was distinctly different from that of the human cells; third, the doubling time of the rabbit cells was shorter; and fourth, the identity of the rabbit cells was verified by chromosome count.

In five cases, the rabbit synovial cell cultures derived from RSC-injected joints had a shortened life-span in vitro or showed prolonged generation times and low confluent densities. These observations are of particular interest because it has been previously reported that human RSC cultures frequently showed a prolonged generation time, shortened culture life-span, and decreased confluent density, as compared to NSC cultures (Smith and Hamerman, 1969; Castor and Dorstewitz, 1966).

(2) No significantly greater degree of histological change could be detected in the group of joints previously injected with human RSC as compared with the controls. This would seem to indicate that the development of arthritis as it is recognized histologically (Hamerman and others, 1969) is not necessarily a precursor, or reflection, of that altered state of synovial cells which makes them able, in vitro, to resist infection with RV or NDV. We had especially looked for depletion of rabbit articular cartilage matrix since this is a finding previously noted to occur early in the course of human rheumatoid arthritis (Janis and Hamerman, 1969) and it has also been observed in cartilage slices incubated with cultured human RSC (Hamerman and others, 1967). The finding that significant synovitis and/or cartilage matrix protein-polysaccharide depletion can occur in joints not injected with any cells at all may reflect spontaneous joint disease, or a reaction to environmental conditions, e.g. caging.

(3) Rabbit synovial cells acquired RV resistance after the injection of human RSC into rabbit joints. In addition, these rabbit cells showed heightened resistance to NDV. These data lend further support to the hypothesis that an 'agent' in the rheumatoid synovial cells is responsible for their altered behaviour both in the intact membrane and in tissue culture.

A number of instances of interference are known where cells containing a virus genome are resistant to superinfection with the same or another virus:

(a) In most tissue culture systems, RV does not produce a cytopathic effect and can only be detected by interference with the cytopathic effect of a challenge virus (usually ECHO 11)(McCarthy and Taylor-Robinson, 1967);

(b) Bryan strain Rous sarcoma virus is always associated with a virus of the avian leucosis complex (Rous associated virus) which is unable to transform chick fibroblasts when multiplying alone, but which renders them resistant to superinfection with the Bryan strain (Rubin and Vogt, 1962);

(c) Non-permissive cells transformed by SV 40 are resistant to superinfection by SV 40 (Butel, Tevethia, and Melnick, 1972; Swetly, BarbantiBrodano, Knowles, and Koprowski, 1969).

RV cannot be linked aetiologically to rheumatoid arthritis either on the basis of the present studies or by virtue of clinical association. It is apparently exceedingly rare to observe rubella infection in humans followed by rheumatoid arthritis. In one such case antibodies to RV persisted for a 'considerably longer time than expected' (Martenis, Bland, and Phillips, 1968). Increased titres of antibody to RV have been found in juvenile patients with rheumatoid arthritis of onset before age 12 (Ogra and Herd, 1972); however, juvenile rheumatoid patients also manifest prolonged high antistreptolysin-O titres (Sievers, Ahvonen, Aho, and Wager, 1963) and thus these findings in the juvenile patients may be due to heightened immune response to selective antigens. This has also been offered as the explanation for the high antibody titres to some myxoviruses observed in patients with systemic lupus erythematosus (Phillips and Christian, 1970).

There have recently appeared reports at variance 
with the present findings, in which $\mathrm{RV}$ replicated to an equal titre as measured in the media of both normal and rheumatoid synovial cells in culture, (Person, Rawls, and Sharp, 1971; Runge and Allison, 1972; Parker, McCollum, and Kerby, 1972). These findings have been reviewed (Ford, 1972) and are obviously of major concern to us. Direct comparison, however, is difficult since there are differences in the experimental methods used. Further studies and exchange of material and protocols will be necessary to resolve these discordant results.

\section{Summary}

Unlike normal synovial membrane cells in culture, rheumatoid synovial cells are resistant to exogenous infection with rubella virus. In an attempt to transfer this trait, human RSC were injected into rabbit joints. Specimens of rabbit synovial membrane obtained 2 to 6 months later were grown in culture and most cultures of rabbit synovial cells were resistant to infection with $R V$.

We wish to thank Mrs. C. Beck and Mrs. H. Harkness for technical assistance.

\section{Addendum}

Resistance of cultured rheumatoid synovial cells to infection with RV and NDV has recently been reported by Patterson, Howard, and Deinhardt (1973), and attributed by them to an increase in the hyaluronic acid content of the rheumatoid cultures.

\section{References}

Bartholomew, L. E., AND Nelson, F. R. (1972) Ann. rheum. Dis., 31, 22 (Corynebacterium acnes in rheumatoid arthritis. 1. Isolation and antibody studies)

Butel, J. S., Tevethia, S. S., AND Melnick, J. I., (1972) Adv. Cancer. Res. 15, 1 (Oncogenicity and cell transformation by papovavirus SV 40: the role of the viral genome)

Castor, C. W. (1971) Arthr. and Rheum. 14, 55 (Connective tissue activation. II. Abnormalities of cultured rheumatoid synovial cells)

AND DORSTEwITZ, E. L. (1966) J. Lab. clin. Med., 68, 300 (Abnormalities of connective tissue cells cultured from patients with rheumatoid arthritis. 1. Relative unresponsiveness of rheumatoid synovial cells to hydrocortisone)

Chayen, J., AND Bitensky, L. (1971) Ann. rheum. Dis., 30, 522 (Lysosomal enzymes and inflammation, with particular reference to rheumatoid diseases)

FORD, D. K. (1972) Arthr. and Rheum., 15, 316 (Viral etiology of rheumatoid arthritis)

Fraser, K. B., Shirodaria, P. V., Haire, M., and Middleton, D. (1971) J. Hyg. (Camb.), 69, 17 (Mycoplasmas in cell cultures from rheumatoid synovial membranes)

Grayzel, A. I., AND BECK, C. (1970) J. exp. Med., 131, 367 (Rubella infection of synovial cells and the resistance of cells derived from patients with rheumatoid arthritis)

Hamerman, D., Barland, P., AND Janis, R. (1969) In 'The Biological Basis of Medicine', ed. E. E. Bittar and N. Bittar, vol. 3, p. 269. Academic Press, New York (The structure and chemistry of the synovial membrane in health and disease)

—, JANIS, R., AND SMITH, C. (1967) J. exp. Med., 126, 1005 (Cartilage matrix depletion by rheumatoid synovial cells in tissue culture)

Hamerton, J. L. (1971) ‘Human Cytogenetics’, vol. 1, General Cytogenetics’. Academic Press, New York

Hoskins, J. M. (1967) 'Virological Procedures', p. 174. Butterworths, London

Hsu, T. C., AND BeniRschKe, K. (1967) 'An Atlas of Mammalian chromosomes, vol. 1, folio 8. Springer-Verlag, New York

JANIS, R., AND Hamerman, D. (1969) Bull. Hosp. Jt Dis., 30, 136 (Articular cartilage changes in early arthritis)

Jansson, E., Mäkisara, P., Vainio, K., Vainio, U., Snellman, O., And TuUri, S. (1971) Ann. rheum. Dis., 30,506 (An 8-year study on mycoplasmas in rheumatoid arthritis)

KopRowsKI, H. (1967) In 'Chronic Infectious Neuropathic Agents (CHINA) and Other Slow Virus Infections', ed. J. A. Brody, W. Henle, and H. Koprowski. Springer-Verlag, New York

MCCARTHY, K., AND TAYLOR-Robinson, C. H. (1967) Brit. med. Bull., 23, 185 (Rubella)

MARCUS, P. I., AND CARVER, D. H. (1965) Science, 149, 983 (Hemadsorption negative plaque test: new assay for rubella virus revealing a unique interference)

Martenis, T. W., Bland, J. H., ANd Phillips, C. A. (1968) Arthr. and Rheum., 11, 683 (Rheumatoid arthritis after rubella)

OGRA, P. L., AND Herd, J. K. (1972) Ibid., 15, 121 (Serologic association of rubella virus infection and juvenile rheumatoid arthritis)

Parker, M. D., McCollum, D. E., AND Kerby, G. P. (1972) Ibid., 15, 275 (Susceptibility of cultures of rheumatoid tissues to rubella virus infection)

Patterson, R., Howard, F., and Deinhart, F. (1973) Clin. Res., 21, 878

Person, D. A., RaWls, W. E., AND Sharp, J. T. (1971) Proc. Soc. exp. Biol. (N. Y.), 138,748 (Replication of rubella, Newcastle disease and vesicular stomatitis viruses in cultured rheumatoid synovial cells)

Phillips, P. E., AND Christian, C. L. (1970) Science, 168, 982 (Myxovirus antibody increases in human connective tissue disease) 
Ropes, M. W., Bennett, G. A., Cobb, S., Jacox, R., AND Jessar, R. A. (1959) Ann. rheum. Dis., 18, 49 (1958 revision of diagnostic criteria for rheumatoid arthritis)

RuBin, H., AND VoGt, P. K. (1962) Virology, 17, 184 (An avian leukosis virus associated with stocks of Rous sarcoma virus)

Runge, L. A., AND Allison, A. C. (1972) Arthr. and Rheum., 15, 85 (Growth of rubella virus in cultures of synovial cells from rheumatoid arthritis)

Sievers, K., AhVonen, P., AHo, K., AND WAGer, O. (1963) Rheumatism, 19, 88 (Serological patterns in juvenile rheumatoid arthritis)

Smiley, J. D., SAChS, C., AND ZifF, M. (1968) J. clin. Invest., 47, 624 (In vitro synthesis of immunoglobulin by rheumatoid synovial membrane)

Smith, C., AND Hamerman, D. (1969) Arthr. and Rheum., 12, 639 (Significance of persistent differences between normal and rheumatoid synovial membrane cells in culture)

Stewart, S. M., AleXander, W. R. M., ANd Duthie, J. J. R. (1969) Ann. rheum. Dis., 28, 477 (Isolation of diphtheroid bacilli from synovial membrane and fluid in rheumatoid arthritis)

Swetly, P., Barbanti-Brodano, G., KNowles, B., aNd Koprowski, H. (1969) J. Virol., 4, 348 (Response of simian virus 40 -transformed cell lines and cell hybrids to superinfection with simian virus 40 and its deoxyribonucleic acid)

Ward, J. R., Cole, B. C., ANd Smith, C. (1972) Presented at the Annual Meeting of the American Rheumatism Association, June, 1972 (Studies on the infectious etiology of human rheumatoid arthritis)

Williams, M. H., Brostoff, H. J., AND Roitt, I. M. (1970) Lancet, 2, 277 (Possible role of Mycoplasma fermentans in pathogenesis of rheumatoid arthritis) 